\title{
ANALISA FAKTOR PENYEBAB KERUSAKAN JALAN KELAS IIIA DI KABUPATEN LAMONGAN
}

\author{
Muhammad Maftukin ${ }^{1}$, Dwi Kartikasari² \\ ${ }^{1}$ Program Studi Teknik Sipil Fakultas Teknik Universitas Islam Lamongan, \\ ${ }^{2}$ Fakultas Teknik Program Studi Teknik Sipil Univesitas Islam Lamongan, \\ email : arjunamaftu@gmail.com, dkartika27@gmail.com
}

\begin{abstract}
Road damage sometimes occurs earlier than the period of service caused by many factors, among others are human factors and natural factors. With the growing number of vehicles, it is possible that the road would be damaged in a relatively short time. The purpose of this study is to know the effect of vehicles volume with the level of road damage and the relationship between the vehicles volume with the level of road damage. In research method, there are several steps that must be done in order to get the results of research that includes doing a preliminary study to know the characteristics of the roads. This research was conducted in the segment of Sekaran Raya Road, Laren Raya Road, Solokuro Raya Road, and Blimbing Paciran Raya Road with the road damage score amounted to 80.2; 85.2; 86.2 and 80.2 respectively. The traffic volume at peak hours respectively amounted 3,375.5 smp/hour, 3,320.2 smp/hour, 2,053.9 smp/hour and 3,832.7 smp/hour. It is known from the result of the traffic volume regression that the road and time damage score is $y=0,002824883 . x 1+0,001498059 . x 2+77.00509615$, with non-linear regression $\left(R^{2}\right)$ or the correlation between the $x$ variables with $y$ is $=0.617977513$, that the higher the traffic volume then the road damage will be even greater.
\end{abstract}

Keywords: Road Damage Score, Traffic Volume, IIIA Road Section

\section{PENDAHULUAN}

Indonesia sebagai negara yang sedang berkembang, dalam rangka meningkatkan penyediaan transportasi darat, maka jalan merupakan faktor penting yang harus diperhatikan dalam pembangunan maupun pemeliharaan. Dalam proses pemeliharaan, kerusakan jalan kadang terjadi lebih dini dari masa pelayanan yang disebabkan oleh adanya banyak faktor, antara lain faktor manusia dan faktor alam. Faktor - faktor alam yang dapat mempengaruhi mutu perkerasan jalan diantaranya air, perubahan suhu, cuaca dan temperatur udara. Sedangkan faktor manusia yaitu diantaranya berupa tonase atau muatan kendaraan - kendaraan berat yang melebihi kapasitas dan volume kendaraan yang semakin meningkat. Dari faktor - faktor itu semua jika terjadi secara terus menerus dapat menyebabkan kerusakan pada jalan yang dilewati, dan tentunya akan merugikan semua pihak - pihak yang terkait (Nugroho , 2013).

Hal tersebut diatas bisa terjadi karena didalam proses perencanaan ada beberapa faktor yang memang sulit atau tidak menentu untuk diprediksikan, seperti jenis kendaraan yang melintas, tingkat pertumbuhan kendaraan yang tidak stabil dan yang paling utama adanya perluasan atau peningkatan kegiatan dijalan yangmembutuhkan daerah manfaat lalu lintas yang lebih besar dari hal hal tersebut diatas, maka perlunya informasi data Lalu Lintas harian Rata-Rata (LHR) 
yaitu dengan perhitungan volume lalu lintas pada jalan sehingga salah satu faktor penyebab terjadinya pembebanan terhadap jalan yang berlebihan dapat dihindari yang pada gilirannya tingkat pelayanan jalan yang optimal dapat dipertahankan.

Kenyataan dilapangan menunjukan bahwa pada jaringan jalan tertentu khususnya diperkotaan terjadi ketidak seimbangan antara tingkat pertumbuhan jalan disatu sisi dengan tingkat pertumbuhan kendaraan disisi yang lain, dimana pertumbuhan jalan jauh lebih kecil daripada tingkat pertumbuhan kendaraan, hal ini berarti menunjukkan terjadinya pembebanan yang belebihan pada jalan. Kondisi semacam ini mengakibatkan terjadinya kerusakan jalan, kenyamanan perjalanan terganggu, tingkat keamanan pengendara. Dimana kesemuanya itu menjurus kearah terjadinya pelanggaran dan kecelakaan lalu lintas. Adapun tujuan dari penelitian yaitu mengetahui pengaruh nilai kerusakan jalan dan hubungan antara volume dengan tingkat kerusakan jalan di jalan aspal kelas IIIA di Kabupeten Lamongan.

\section{METODE PENELITIAN}

Pada metode penelitian terdapat beberapa langkah yang harus dilakukan agar mendapatkan hasil penelitian yang meliputi studi pendahuluan untuk mengetahui karakteristik ruas jalan. Dilanjutkan dengan menentukan tempat survey. Langkah selanjutnya adalah identifikasi permasalahan merupakan pengenalan masalah yang akan dibahas lalu dilanjutkan dengan pengumpulan data primer dan data sekunder.

Lokasi penelitian merupakan ruas jalan kelas IIIA di Kabupaten Lamongan, antara lain: Jalan Raya Sekaran, jalan raya Laren, Jalan Raya Solokuro, Jalan Raya Blimbing Paciran. Survei kerusakan jalan dilakukan di Kabupaten Lamongan dimulai pada 12 Mei 2016dan 30 Mei 2016 Waktu pelaksanaan dilakukan pada pukul 06.00 WIB - selesai.

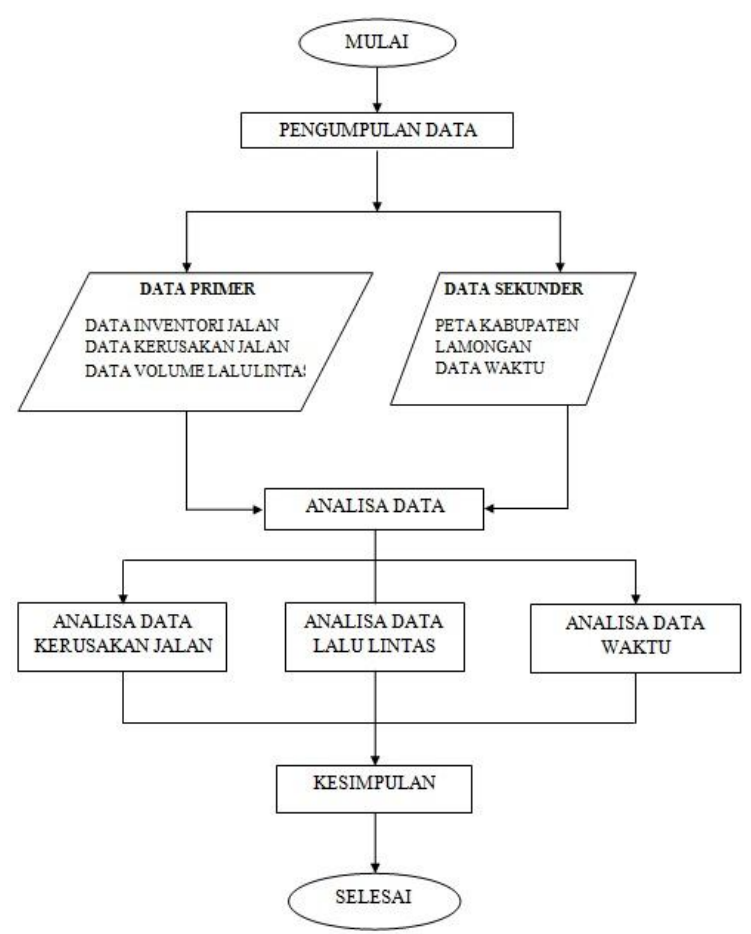

Gambar 1. Diagram Alur Penelitian

\section{HASIL PENELITIAN Daerah Penelitian}

Jalan yang menjadi obyek dalam penelitian ini berada di wilayah Kabupaten Lamongan, dengan kelas, Jalan IIIA yang meliputi jalan raya Sekaran, Laren, Solokuro dan Blimbing.

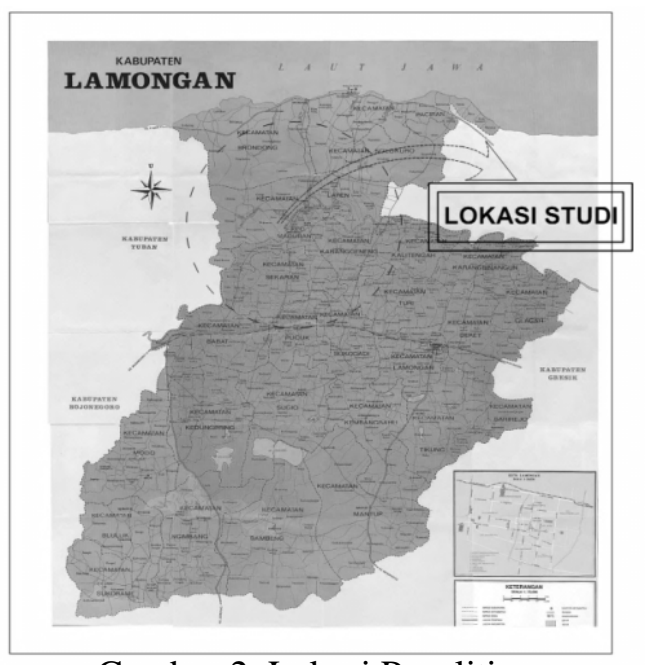

Gambar 2. Lokasi Penelitian 
Tabel 1. Pengamatan Jalan

\begin{tabular}{lcccc}
\hline \multicolumn{3}{c}{ Nama Jalan } & \\
\hline Data Inventori & $\begin{array}{c}\text { Jalan } \\
\text { Sekaran }\end{array}$ & $\begin{array}{c}\text { Jalan } \\
\text { Raya } \\
\text { Laren }\end{array}$ & $\begin{array}{c}\text { Jalan } \\
\text { Raya } \\
\text { Solokuro }\end{array}$ & $\begin{array}{c}\text { Jalan Raya } \\
\text { Blimbing } \\
\text { Paciran }\end{array}$ \\
\hline Panjang ruas (km) & 1 & 2,5 & 2 & 1 \\
Jumlah Jalur & 2 & 2 & 2 & 2 \\
Jumlah Lajur & 2 & 2 & 2 & 2 \\
Lebar Ruas (m) & 5 & 6 & 6 & 5 \\
Median & Tidak & Tidak & Tidak & Tidak \\
Jenis Kontruksi & Aspal & Aspal & Aspal & Aspal \\
Jalan & & & & \\
\hline \multicolumn{1}{c}{ Sumber: } & & & &
\end{tabular}

Sumber : Hasil Pengamatan

\section{Data Kerusakan Jalan}

Data kerusakan jalan diperoleh dari data primer, yaitu mensurvei langsung di lapangan. Data ini berisi data dimensi dan luas kerusakan jalan berdasarkan klasifikasi kerusakan jalan dari Dinas Bina Marga, yaitu berupa tambalan, retak, lepas, lubang, alur, gelombang, dan amblas.

Cara perhitungannya dimulai dari data dimensi kerusakan jalan tersebut dihitung menjadi satuan luas yang kemudian dibandingkan dengan luas jalan yang ditinjau. Kemudian dari hasil perbandingan tersebut akan muncul hasil berupa prosentase. Hasil prosentase ini disebut dengan nilai prosentase kerusakan $(\mathrm{Np})$, dari nilai prosentase kerusakan ini maka akan dibagi menjadi 4 (empat) kategori tingkat kerusakan, yaitu : jika $<5 \%$ maka nilainya adalah 2,5\% - 20\% maka nilainya adalah 3 . $20 \%$ - 40\% maka nilainya 5 dan jika $>40 \%$ maka nilainya 7. 40. Setelah didapatkan nilai $\mathrm{Np}$, maka langkah selanjutnya adalah memasukkan bobot nilai kerusakan jalan $(\mathrm{Nj})$, bobot nilai ini sudah ditentukan oleh Dinas Bina Marga.

Tabel 2. Bobot Nilai Kerusakan Jalan (Nj)

\begin{tabular}{clc}
\hline No & \multicolumn{1}{c}{ Jenis Kerusakan } & Nj \\
\hline 1 & Konstruksi beton tanpa kerusakan & 2 \\
2 & Konstruksi penetrasi tanpa & 3 \\
3 & kerusakan & 4 \\
4 & Tambalan & 5 \\
5 & Lepak & 5,5 \\
6 & Lubang & 6 \\
7 & Alur & 6 \\
\hline
\end{tabular}

\begin{tabular}{clc}
\hline No & \multicolumn{1}{c}{ Jenis Kerusakan } & Nj \\
\hline 8 & Gelombang & 6,6 \\
9 & Amblas & 7 \\
10 & Belahan & 7 \\
\hline Sumber $:$ Bina Marga
\end{tabular}

Kemudian jika sudah didapatkan nilai $\mathrm{Np}$ dan $\mathrm{Nj}$, selanjutnya menghitung nilai $\mathrm{Nq}$, yaitu nilai jumlah kerusakan. Besarnya nilai jumlah kerusakan $(\mathrm{Nq})$ diperoleh dari perkalian antara nilai $\mathrm{Np}$ dengan nilai $\mathrm{Nj}$. Sebagai contoh jika kerusakan jalan berupa retak dengan nilai $\mathrm{Np}=5$ dan nilai $\mathrm{Nj}=5$, maka nilai $\mathrm{Nq}$ adalah 25 , yang berarti tingkat kerusakan jalan untuk retak adalah sedang, dan begitupun selanjutnya.

Data dimensi kerusakan setiap jenis kerusakan jalan dapat dilihat pada Lampiran 1 dan data nilai kerusakan jalan (Nr) yang diperoleh dalam penelitian ini.

\section{Data Volume Lalu Lintas}

Jalan - jalan di Kabupaten Lamongan yang menjadi daerah penelitian, merupakan jalan - jalan utama masyarakat untuk pindah dari satu tempat ke tempat lain.

Data volume lalu lintas yang didapatkan merupakan data yang disurvei langsung pada lokasi studi. Data tersebut digunakan untuk mengetahui letak jam puncak dari volume lalu lintas yang terjadi di jalan - jalan yang menjadi daerah penelitian di Kabupaten Lamongan. Dari data ini kemudian digunakan sebagai acuan dalam penentuan waktu yang akan dipakai untuk menghitung kembali volume lalu lintas yang terjadi pada jam puncak, agar data yang didapatkan lebih valid, sekaligus sebagai data primer dalam penelitian ini.

Dalam data primer ini, survei counting yang dilakukan hanya 2 (dua) jam saja, karena data volume lalu lintas yang dibutuhkan hanya pada saat jam puncak saja, sebagai contoh jika jam puncak dari data sekunder terjadi pada pukul $06.00-08.00$ WIB, Dari data survey yag dilakukan terdapat data lalu lintas harian rata-rata dapat dilihat dari tabel berikut : 
Tabel 3. Perhitungan Volume Lalu Lintas Jalan Raya Sekaran

\begin{tabular}{|c|c|c|c|c|}
\hline No & $\begin{array}{l}\text { Jenis } \\
\text { kendaraan }\end{array}$ & $\begin{array}{l}\text { Jumlah } \\
\text { kendaraan }\end{array}$ & (emp) & $\begin{array}{c}\text { Vol. lalu } \\
\text { lintas } \\
\text { ( smp ) }\end{array}$ \\
\hline 1 & $\begin{array}{l}\text { Sepeda } \\
\text { Motor }\end{array}$ & 1.587 & 0,5 & 3.174 \\
\hline 2 & $\begin{array}{l}\text { Kendaraan } \\
\text { Ringan }\end{array}$ & 183 & 1,0 & 183 \\
\hline 3 & Bus Besar & 0 & 1,39 & 0 \\
\hline 4 & $\begin{array}{l}\text { Kendaraan } \\
\text { Menengah }\end{array}$ & 30 & 1,67 & 18,51 \\
\hline \multicolumn{2}{|c|}{ Jumlah } & 1.800 & 4,51 & 3375,51 \\
\hline
\end{tabular}

Sumber : Hasil Perhitungan

Tabel 4. Perhitungan Volume Lalu Lintas Jalan Raya Laren

\begin{tabular}{|c|c|c|c|c|}
\hline No & $\begin{array}{l}\text { Jenis } \\
\text { kendaraan }\end{array}$ & $\begin{array}{c}\text { Jumlah } \\
\text { kendaraan }\end{array}$ & (emp) & $\begin{array}{c}\text { Vol. lalu } \\
\text { lintas } \\
\text { ( smp ) }\end{array}$ \\
\hline 1 & $\begin{array}{l}\text { Sepeda } \\
\text { Motor }\end{array}$ & 1.571 & 0,5 & 3.147 \\
\hline 2 & $\begin{array}{l}\text { Kendaraan } \\
\text { Ringan }\end{array}$ & 161 & 1,0 & 161 \\
\hline 3 & Bus Besar & 0 & 1,39 & 0 \\
\hline 4 & $\begin{array}{l}\text { Kendaraan } \\
\text { Menengah }\end{array}$ & 28 & 1,67 & 17,28 \\
\hline \multicolumn{2}{|c|}{ Jumlah } & 1.760 & 4,51 & 3320,29 \\
\hline
\end{tabular}

Sumber : Hasil Perhitungan

Tabel 5. Perhitungan Volume Lalu Lintas Jalan Raya Solokuro

\begin{tabular}{|c|c|c|c|c|}
\hline No & $\begin{array}{l}\text { Jenis } \\
\text { kendaraan }\end{array}$ & $\begin{array}{c}\text { Jumlah } \\
\text { kendaraan }\end{array}$ & (emp) & $\begin{array}{c}\text { Vol. lalu } \\
\text { lintas } \\
(\mathrm{smp})\end{array}$ \\
\hline 1 & $\begin{array}{l}\text { Sepeda } \\
\text { Motor }\end{array}$ & 972 & 0,5 & 1.944 \\
\hline 2 & $\begin{array}{l}\text { Kendaraan } \\
\text { Ringan }\end{array}$ & 97 & 1,0 & 97 \\
\hline 3 & Bus Besar & 0 & 1,39 & 0 \\
\hline 4 & $\begin{array}{l}\text { Kendaraan } \\
\text { Menengah }\end{array}$ & 21 & 1,67 & 12,96 \\
\hline \multicolumn{2}{|c|}{ Jumlah } & 1.090 & 4,51 & 2053,96 \\
\hline
\end{tabular}

Sumber : Hasil Perhitungan
Tabel 6. Perhitungan Volume Lalu Lintas Jalan Raya Blimbing Paciran

\begin{tabular}{|c|c|c|c|c|}
\hline No & $\begin{array}{l}\text { Jenis } \\
\text { kendaraan }\end{array}$ & $\begin{array}{c}\text { Jumlah } \\
\text { kendaraan }\end{array}$ & (emp) & $\begin{array}{c}\text { Vol. lalu } \\
\text { lintas } \\
\text { ( smp ) }\end{array}$ \\
\hline 1 & $\begin{array}{l}\text { Sepeda } \\
\text { Motor }\end{array}$ & 1.791 & 0,5 & 3.582 \\
\hline 2 & $\begin{array}{l}\text { Kendaraan } \\
\text { Ringan }\end{array}$ & 231 & 1,0 & 231 \\
\hline 3 & Bus Besar & 0 & 1,39 & 0 \\
\hline 4 & $\begin{array}{l}\text { Kendaraan } \\
\text { Menengah }\end{array}$ & 32 & 1,67 & 19,75309 \\
\hline \multicolumn{2}{|c|}{ Jumlah } & 2.054 & 4,51 & 3832,753 \\
\hline
\end{tabular}

Data primer yang digunakan dalam analisa pengaruh jumlah kendaraan terhadap kerusakan jalan dalam penelitian ini yaitu data angka jumlah volume kendaraan pada jam puncak dalam satuan smp/jam. Rekap volume lalu lintas dalam satuan kendaraan/jam dapat dilihat pada Tabel 6.

Tabel 7. Volume Lalu Lintas Pada Jam Puncak (smp/jam)

\begin{tabular}{lc}
\hline \multicolumn{1}{c}{ Nama Jalan } & $\begin{array}{c}\text { Volume lalu } \\
\text { lintas (smp/jam) }\end{array}$ \\
\hline Jalan Raya Sekaran & $3.375,5$ \\
Jalan Raya Laren & $3.320,2$ \\
Jalan Raya Solokuro & $2.053,9$ \\
Jalan Raya Blimbing & $3.832,7$ \\
Paciran &
\end{tabular}

Pada Tabel 7.terjadi perubahan selisih angka pada volume lalu lintas yang menjadi lebih sedikit, perbedaan yang sangat signifikan dapat dilihat pada jalan Raya Sekaran dengan jalan Raya Blimbing Paciran, hal ini sangat berbeda jika dibandingkan berdasarkan kendaraan/jam. Perbedaan tersebut terjadi akibat jenis atau komposisi kendaraan yang berbeda - beda yang melintasi jalan tersebut. Oleh sebab itu untuk menyamakan satuan volume lalu lintas yang akan digunakan harus dikonversi menjadi satuan mobil penumpang (smp), 
yang tujuannya untuk menyamakan satuan di setiap jenis atau komposisi kendaraan.

\section{Data Waktu}

Waktu merupakan suatu faktor yang sangat penting dalam suatu konstruksi, salah satunya pada konstruksi jalan, hal ini dikarenakan jalan mempunyai umur rencana yang terbatas, sebagai contoh jika jalan menggunakan perkerasan lentur atau aspal, umur rencananya adalah 10 tahun dan jalan dengan perkerasan kaku atau beton, maka umur rencananya adalah 20 tahun. Data waktu pada penelitian ini merupakan data sekunder yang diperoleh dari Direktorat Jendral Bina Marga Satuan Kerja Lamongan, data waktu ini hanya didapatkan secara lisan saja, karena untuk data secara tertulis waktu terakhir jalan tersebut diperbaiki atau ditingkatkan tidak ada. Data waktu yang didapatkan hanya berupa data bulan dan tahun waktu terakhir jalan tersebut diperbaiki atau ditingkatkan. Tetapi untuk analisa dalam penelitian ini data waktu tersebut harus diubah menjadi satuan jam, karena analisa ini saling berhubungan dengan analisa volume kendaraan yang menggunakan satuan per jam. (lihat Tabel 7.)

\section{Tabel 8. Perhitungan Waktu Dalam Satuan Jam}

\begin{tabular}{|c|c|c|c|c|}
\hline $\begin{array}{c}\text { Nama } \\
\text { Jalan }\end{array}$ & $\begin{array}{c}\text { Waktu } \\
\text { Terakhir } \\
\text { Diperbaiki }\end{array}$ & $\begin{array}{l}\text { Waktu } \\
\text { Disurvei }\end{array}$ & $\begin{array}{c}\text { Umur } \\
\text { Jalan } \\
\text { (bulan) }\end{array}$ & Jam \\
\hline $\begin{array}{l}\text { Jalan Raya } \\
\text { Sekaran }\end{array}$ & April 2015 & $\begin{array}{c}\text { Mei } \\
2016\end{array}$ & 14 & 10.080 \\
\hline $\begin{array}{l}\text { Jalan Raya } \\
\text { Laren }\end{array}$ & April 2015 & $\begin{array}{l}\text { Mei } \\
2016\end{array}$ & 14 & 10.080 \\
\hline $\begin{array}{l}\text { Jalan Raya } \\
\text { Solokuro }\end{array}$ & April 2015 & $\begin{array}{c}\text { Mei } \\
2016\end{array}$ & 14 & 10.080 \\
\hline $\begin{array}{l}\text { Jalan Raya } \\
\text { Blimbing } \\
\text { Paciran }\end{array}$ & Mei 2015 & $\begin{array}{c}\text { Mei } \\
2016\end{array}$ & 13 & 9.360 \\
\hline
\end{tabular}

Sumber : Hasil Perhitungan

Perhitungan waktu pada Tabel 8. ini dimulai dari perhitungan selisih bulan antara waktu terakhir jalan tersebut diperbaiki atau ditingkatkan sampai waktu jalan tersebut disurvei kembali. Setelah itu didapatkan hasil dalam satuan bulan, kemudian satuan bulan tersebut dikonversi menjadi satuan jam dengan cara jumlah bulan tersebut dikalikan dengan 30 hari dan dikalikan dengan 24 jam.

Sebagai contoh adalah pada Tabel 8. didapatkan hasil bahwa pada Jalan Raya Sekaran umur jalan yang dihasilkan 14 bulan yang kemudian dikonversi menjadi 10.080 jam, Jalan Raya Laren umur jalan yang dihasilkan 14 bulan yang kemudian dikonversi menjadi 10.080 jam, Jalan Raya Solokuro umur jalan yang dihasilkan 14 bulan yang kemudian dikonversi menjadi 10.080 jam, dan Jalan Raya Blimbing Paciran umur jalan yang dihasilkan 13 bulan dan dikonversi menjadi 9.360 jam.

\section{Hubungan Analisa Data}

Volume lalu lintas dan waktu sebagai variabel $\mathrm{x}$, yang masing - masing adalah $\mathrm{x} 1$ dan $\mathrm{x}$, , sedangkan kerusakan jalan sebagai variabel y. Pada hasil persamaan yang digunakan adalah persamaan $\mathrm{y}=\mathrm{ax} 1+\mathrm{ax} 2+$ c, karena terdapat 2 (dua) variabel $x$, yaitu volume lalu lintas dan waktu, karena waktu merupakan salah faktor yang sangat berpengaruh dalam kerusakan jalan, dan 1 (satu) variabel y, yaitu nilai kerusakanjalan. Rekapitulasi antara variabel $\mathrm{x}$ dan $\mathrm{y}$ dapat dilihat pada Tabel 8 .

\section{Tabel 9. Rekapitulasi Variabel X dan Y}

\begin{tabular}{lccc}
\hline \multicolumn{1}{c}{ Nama Jalan } & $\begin{array}{c}\text { Volume } \\
(\mathbf{s m p / j a m})\end{array}$ & $\begin{array}{c}\text { Waktu } \\
(\mathbf{J a m})\end{array}$ & \multirow{2}{*}{$\mathbf{N r}(\mathbf{y})$} \\
\cline { 2 - 3 } & $\mathbf{( x 1 )}$ & $\mathbf{( x 2 )}$ & \\
\hline $\begin{array}{l}\text { Jalan Raya } \\
\text { Sekaran }\end{array}$ & $3.375,5$ & 10.080 & 80,2 \\
\hline $\begin{array}{l}\text { Jalan Raya Laren } \\
\text { Jalan Raya }\end{array}$ & $3.320,2$ & 10.080 & 85,2 \\
$\begin{array}{l}\text { Solokuro } \\
\text { Jalan Raya } \\
\text { Blimbing Paciran }\end{array}$ & $3.053,9$ & 10.080 & 86,2 \\
\hline
\end{tabular}

Sumber : Hasil Perhitungan 
Tabel 10. Persamaan Hubungan Antara Variabel X dan Y

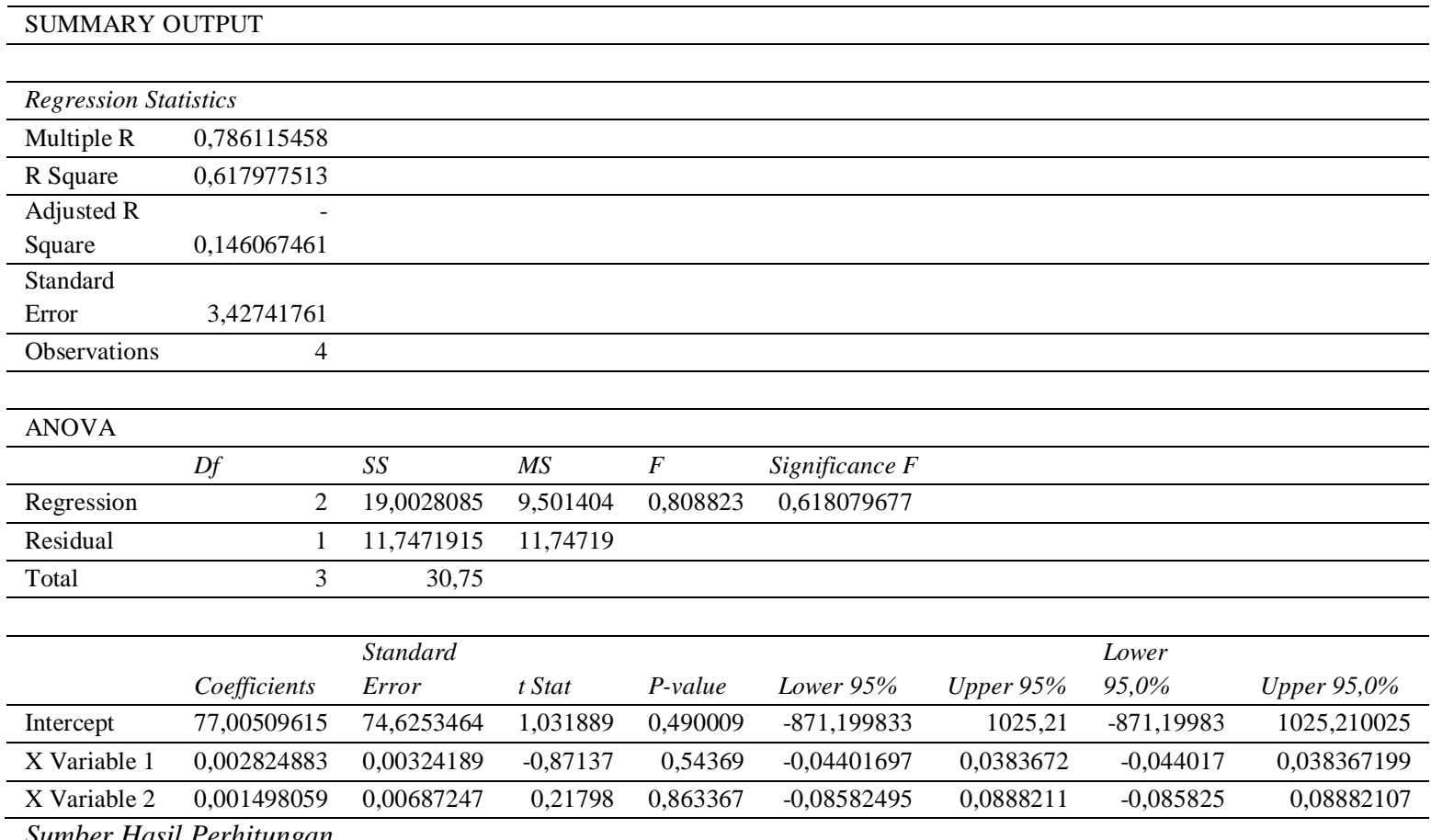

Tabel 11. Contoh Hasil Perhitungan Nilai Y (Kerusakan Jalan)

$y=0,002824883 \cdot x 1+0,001498059 \cdot x 2+77,00509615$,

\begin{tabular}{|c|c|c|c|c|c|c|c|c|c|c|c|c|}
\hline \multirow[t]{2}{*}{$\begin{array}{l}\text { Volume } \\
\text { (smp/jam) } \\
(\mathbf{x 1}) \\
\end{array}$} & \multicolumn{12}{|c|}{$\begin{array}{l}\text { Waktu (jam) } \\
(\mathrm{x} 2)\end{array}$} \\
\hline & 0 & 1000 & 2000 & 3000 & 4000 & 5000 & 6000 & 7000 & 8000 & 9000 & 10000 & 11000 \\
\hline 0 & $\mathbf{0}$ & & & & & & & & & & & \\
\hline 500 & & 79,9 & & & & & & & & & & \\
\hline 1000 & & & 82,8 & & & & & & & & & \\
\hline 1500 & & & & 85,7 & & & & & & & & \\
\hline 2000 & & & & & 88,6 & & & & & & & \\
\hline 2500 & & & & & & 91,5 & & & & & & \\
\hline 3000 & & & & & & & 94,4 & & & & & \\
\hline 3500 & & & & & & & & 97,3 & & & & \\
\hline 4000 & & & & & & & & & 100,28 & & & \\
\hline 4500 & & & & & & & & & & 103,19 & & \\
\hline 5000 & & & & & & & & & & & 106,11 & \\
\hline 5500 & & & & & & & & & & & & 109,02 \\
\hline
\end{tabular}

Sumber Hasil Perhitungan

\section{KESIMPULAN}

Kesimpulan dalam penelitian ini adalah nilai kerusakan jalan (Nr) di Jalan Raya
Sekaran, Jalan Raya Laren, Jalan Raya Solokuro, dan Jalan Raya Blimbing Paciran secara berturut - turut adalah 80,$2 ; 85,2 ; 86,2$ 
dan 80,2. dengan nilai prosentase nilai kurang dari 5\% maka tingkat kerusakan kategori sedikit sekali. Volume lalu lintas pada jam puncak berdasarkan satuan mobil penumpang (smp)/jam Jalan Raya Sekaran, Jalan Raya Laren, Jalan Raya Solokuro, Jalan Raya Blimbing Paciran secara berturut - turut adalah 3.375,5 smp/jam, 3.320,2 smp/jam, $2.053,9 \mathrm{smp} / \mathrm{jam}$ dan 3.832,7 smp/jam. Dilihat dari hasil regresi volume lalu lintas, nilai kerusakan jalan dan waktu adalah $\boldsymbol{y}=$ $0,002824883 . x 1+0,001498059 . x 2+$ 77,00509615 , dengan regresi non linear $\left(\mathrm{R}^{2}\right)$ atau korelasi antara variabel $\mathrm{x}$ dengan y yaitu $=0,617977513$, diketahui bahwa semakin tinggi volume lalu lintas maka kerusakan jalan juga akan semakin besar.

\section{REFERENSI}

Dewi H. U. N, 2010, Analisa Optimasi Jaringan Jalan Berdasar Kepadatan Lalulintas di Wilayah Semarang dengan Berbantuan Sistem Informasi Geografi. (Studi Kasus Wilayah Dati II Semarang), Universitas Stikubank Semarang.

Eko A. N, 2013, Pengaruh Jumlah Kendaraan Terhadap Kerusakan Jalan Aspal Kelas IIA Di Kabupaten Semarang, Universitas Negeri Semarang.

Elly T.P 2006. Manajemen Transportasi Jalan dan Perencanaan, Jakarta

Hendarsin S. L, 2000. Perencanaan Teknik Jalan Raya Bandung :Politeknik Negeri Bandung.

Homburger W.S.1992. Perkins, Fundamental of Traffic Engineering, $13 \mathrm{Th}$ edition,Institute of Transportation Studies, University of California at Berkeley

Khisty, 2003. Manajemen Kontrusi Jalan, Jakarta.Universitas Sumatera Utara, Sumatera Utara.

Oglesby,1999. Rekayasa Lalu Lintas, Semarang.Universitas Sumatera Utara, Sumatera Utara.
Philip L. (2007): Economics of Travel Demand Management: Comparative Cost Effectiveness and Public Investment. Center For Urban Transportation Reserch.

Sukirman, 1994. Manajemen Lalu Lintas Perkotaan Negeri Bandung, Universitas Negeri Bandung, Bandung

Sulaksono, 2001. Manajemen Transportasi Darat, Semarang, Universitas Negeri Semarang.

Soeratno, 2003. Observasi pengamatan kerusakanjalan. Citra Aditya Bakti Bandung, Bandung.

http://ppsdmd.bpsdm.dephub.go.id/73) 23 Mei 2016, 16:30 WIB. 
Halaman ini sengaja dikosongkan 